\title{
Canadian Society for Exercise Physiology Position Paper: Resistance Training in Children and Adolescents
}

\author{
Authors: David G. Behm ${ }^{1}$ Avery D. Faigenbaum², Baraket Falk ${ }^{3}$, \\ Panagiota Klentrou ${ }^{3}$, \\ 1. School of Human Kinetics and Recreation, \\ Memorial University of Newfoundland \\ St. John's Newfoundland, Canada, A1C 5S7 \\ 2. Department of Health and Exercise Science \\ The College of New Jersey \\ PO Box 7718, Ewing, NJ. USA 08628-0718 \\ 3. Department of Physical Education \& Kinesiology \\ Brock University \\ St. Catharines, Ontario, Canada L2S 3A1
}




\begin{abstract}
Many position stands and review papers have refuted the myths associated with resistance training (RT) in children and adolescents. With proper training methods, RT for children and adolescents can be relatively safe and improve overall health. The objective of this position paper and review is to highlight research and provide recommendations in aspects of RT that have not been extensively reported in the pediatric literature. In addition to the well-documented increases in muscular strength and endurance, RT has been used to improve function in pediatric patients with cystic fibrosis, cerebral palsy and burn victims. Increases in children's muscular strength have been attributed primarily to neurological adaptations due to the disproportionately higher increase in muscle strength than in muscle size. Although most studies using anthropometric measures have not shown significant muscle hypertrophy in children, more sensitive measures such as magnetic resonance imaging and ultrasound have suggested hypertrophy may occur. There is no minimum age for RT for children. However the training and instruction must be appropriate for children and adolescents involving a proper warm-up, cool-down and an appropriate choice of exercises. It is recommended that low-to-moderate intensity resistance should be utilized 2-3 times per week on non-consecutive days, with 1-2 sets initially, progressing to 4 sets of 8-15 repetitions for 8-12 exercises. These exercises can include more advanced movements such as Olympic style lifting, plyometrics and balance training, which can enhance strength, power, co-ordination and balance. However specific guidelines for these more advanced techniques need to be established for youth. In conclusion, a RT program that is within a child's or adolescent's capacity, involves gradual progression under qualified
\end{abstract}


instruction and supervision with appropriately sized equipment can involve more advanced or intense RT exercises which can lead to functional (i.e. muscular strength, endurance, power, balance and co-ordination) and health benefits.

Key Words: youth, pediatric, exercise, health, strength 


\section{Definition of Terms}

For the purpose of this paper, the term children refer to boys and girls who have not yet developed secondary sex characteristics (approximately up to age 11 in girls and 13 in boys; Tanner stages 1 and 2 of sexual maturation). This period of development is often referred to as preadolescence. The term adolescence refers to the period of time between childhood and adulthood and includes girls aged 12 to 18 years and boys aged 14 to 18 years (Tanner stages 3 and 4 of sexual maturation). The term youth is broadly defined in this paper to include the years of childhood and adolescence. The term resistance training refers to a specialized method of conditioning that involves the progressive use of a wide range of resistive loads, including body weight and a variety of training modalities

designed to enhance health, fitness and sports performance. While the terms resistance training, strength training and weight training are sometimes used synonymously, the term resistance training encompasses a broader range of training modalities and a wider variety of training goals. The term weightlifting refers to a competitive sport that involves the snatch and clean and jerk lifts. 


\section{Introduction}

The conclusions regarding the beneficial effects of resistance training (RT) for pre-adolescent children and adolescents has been consistently positive in the scientific literature. The concerns and myths that were pervasive throughout the general population have been persistently refuted in the scientific literature. Some of these myths purported that RT for children would result in stunted growth, epiphyseal plate damage, lack of strength increases due to a lack of testosterone and a variety of safety issues (Blimkie, 1993). There has been a universal acceptance in various association position papers (American Academy of Pediatrics, 2001; American College of Sports Medicine, 2006; British Association of Sport and Exercise Sciences, 2004; Faigenbaum et al. 1996b; Golan et al. 1998; Smith et al. 1993) and review articles (Blimkie 1993; Blimkie 1992; Faigenbaum 2000; Falk and Eliakim 2003; Falk and Tenenbaum 1996; Hass et al. 2001; Malina 2006; McNeely and Armstrong 2002; Payne et al. 1997; Sale 1989; Webb 1990) that RT for children will improve muscular strength and muscular endurance if performed under the supervision of a qualified instructor, using proper technique, gradual training progressions and a proper warm-up and cool down. These strength gains are relatively comparable to adolescent or adult strength gains but do not typically provide substantial gains in muscle size (Blimkie 1993; Blimkie 1992). Falk and Tenebaum (1996) conducted a meta-analysis and reported RT-induced strength increases of 13-30\% in preadolescent children following RT programs of 8-20 weeks.

Rather than contributing to injuries as was previously thought, RT has been reported to be safe (when supervised and with proper technique) for children and to potentially decrease the incidence and severity of sport injuries (Faigenbaum et al. 1996b; 
Falk and Eliakim 2003; Hamill 1994; McNeely and Armstrong 2002; Smith et al. 1993; Webb 1990). Furthermore RT has been reported to increase bone mineral density (Nichols et al. 2001) while not adversely affecting maturational growth (Sadres et al. 2001), cardiorespiratory fitness, resting blood pressure (Blimkie 1993) and either has no effect or improves body composition (Faigenbaum et al. 1993; Hass et al. 2001; Lillegard et al. 1997; Sadres et al. 2001; Siegal et al. 1989; Sothern et al. 2000). In addition, RT can have a positive effect on other health and fitness-related measures (Faigenbaum 2000) including the blood lipid profile (Hass et al. 2001). Psychosocial skills and measures of well being can be enhanced with RT (Faigenbaum et al. 1996b; Falk and Eliakim 2003; Hass et al. 2001) as well as motor control skills or performance (Faigenbaum 2000; Falk and Eliakim 2003; Hass et al. 2001) and co-ordination (Blimkie 1993). Although there is some diversity of opinion on whether sports performance is directly improved with RT, it appears that regular participation in a sport-specific resistance training program can result in some degree of improvement in athletic performance in young athletes (Faigenbaum et al, 1996b; Falk and Eliakim 2003; McNeely and Armstrong 2002; Webb, 1990). The current literature generally agrees that low-to-moderate intensity resistance should be utilized (Golan et al. 1998; Hass et al. 2001), 2-3 times per week on non-consecutive days, with 1-4 sets of 6-20 repetitions for 6-12 exercises and generally through a full range of motion (Faigenbaum et al. 1996b; Golan et al. 1998; Malina 2006; McNeely and Armstrong 2002; Webb 1990). Thus, if it is now well accepted among sports and medical associations that RT is effective and beneficial for children and adolescents, is there any necessity for another position paper or review on this matter? 
While the benefits and prescriptions for standard RT programs are well established, there are a number of relatively new or more advanced RT concepts that have not been comprehensively addressed in the pediatric literature. More advanced training concepts such as plyometrics, instability RT, periodization, Olympic style weightlifting, testing methods and others have been well documented in the adult literature but have received much less exposure or research in the pediatric literature and may be somewhat controversial. It is important to highlight new knowledge in these areas or alert the professionals to the lack of information and the possibility of future research directions in the area of pediatric RT. Thus, it is the objective of this position paper to highlight the major findings related to new trends in pediatric RT, the benefits and the mechanisms underlying the training adaptations in children, provide training recommendations and to illustrate areas that need more research.

\section{Health Benefits}

In the past, RT was not recommended for children as it was believed to be ineffective in terms of strength improvements while at the same time could lead to injuries, and long term health consequences such as damage of growth plates and premature closure of epiphyses. However, recent studies are finding positive results with such practice and have proven RT to actually be beneficial to this population (Steinberger 2003). There is actually an increasing amount of evidence suggesting that RT has the potential to increase bone mineral density, develop greater muscle strength and endurance, maintain lean body mass, as well as provide a rehabilitation vehicle for various other conditions that impair growth such as cystic fibrosis and osteopenia in both 
pre- and post-adolescence youth. RT can also lead to improvements in motor skills and performance while helping resist injury and building up a positive attitude by increasing confidence levels and self-esteem (Faigenbaum 2007; Hass et al. 2001; Suman et al. 2001). Accordingly, strong emphasis relies upon ensuring proper technique and considering confounding variables, such as the type and length of the training program. For optimal outcome, the RT program should be designed specifically in conjunction with the age, gender, health status and physical fitness of the child involved. Table 1 presents a summary of studies on the health related effects of RT in children and adolescents.

\section{INSERT TABLE 1 HERE}

Muscular strength and endurance of children and adolescents have been shown to significantly improve beyond normal growth and maturation when practicing a specifically designed RT program (Benson et al. 2007; Faigenbaum et al. 1999; Falk and Mor, 1996; Ramsay et al. 1990). To control for growth and maturation effects, the majority of RT studies included an age-matched control group and have shown that over a period of 6-20 weeks, muscle strength and performance increased to a greater extent in children who participated in RT, compared with those who did not. More specifically, it has been reported that moderate loads (ex. 50-60\% of 1RM) and higher repetitions (ex. 15-20 reps) may be most beneficial for enhancing muscular strength and endurance in youth during the initial adaptation period (Benson et al. 2007; Christou et al. 2006; Faigenbaum et al. 1999; Faigenbaum et al. 2005; Lillegard et al. 1997; Pfeiffer and Francis 1986). Overall, in a recent summary by Malina (2006), the 22 reviewed studies agreed that RT of two to three times per week resulted in significant improvements in 
muscle strength during childhood and adolescence while minimal injuries were reported. Significant gains have been reported in isometric and isokinetic strength, muscular endurance and flexibility with RT protocols of different frequencies and duration, and across maturity levels (Blimkie et al.1989; Faigenbaum et al.1993, 1999, 2001; 2005; Rians et al.1987; Ramsay et al.1990; Sailors and Berg 1987; Weltman et al. 1986). These training-induced improvements were in some cases more evident in older boys and greater in lower than upper body strength, and with 2 days/week compared to 1 day/week (Pikosky et al. 2002; Vrijens 1978; Faigenbaum et al. 2002). A 12-week school based RT program also resulted in significant improvements of strength, endurance and flexibility in pre-pubertal boys and girls as compared with their control counterparts (Siegal et al. 1989). In addition, an injury-free 12 -week combined program of resistance and martial arts exercises showed improvements in physical performance tasks reflecting muscle strength, endurance, power and coordination (Falk and Mor 1996). Strength training can also augment the muscle enlargement that normally occurs with pubertal growth in males and females (Kraemer et al. 1989; Webb 1990) but the magnitude of changes in children's cross-sectional muscle area is smaller than this found in adults (Fukunaga et al. 1992; Mersch and Stoboy 1989). It should also be noted that gains in muscle strength and power begin to regress towards untrained values if RT is discontinued (Faigenbaum et al. 1996a; Tsolakis et al. 2004).

Bone health is another area of study when considering health benefits of RT (Table 1). Bass et al. (1998) have reported that pre-pubertal female gymnasts, whose training mainly involves high impact and resistance training, had significantly higher bone mineral density (BMD) than age-matched controls. Lumbar spine bone mass, 
volume and volumetric BMD were also higher in the gymnasts than those found in the control group. They also showed that endocortical diameter was lower in the control group suggesting an increased cortical thickness in the gymnasts. The gymnasts, however, were growing at a slower rate than the controls when comparing sitting height, femur height and length, and tibia length. This does not seem to be related to the training but is rather a result of selection because of an advantage of shorter athletes in the sport (Daly et al. 2000; Erlandson et al. 2008; Gurd and Klentrou 2003). In a more recent study, Ward et al. (2005) also compared the bone size of the peripheral and axial skeleton among pre-pubertal gymnasts, swimmers and controls. After adjustment for age and gender, they found that male pre-pubertal gymnasts had significantly thicker cortical bone at the tibia and radius than the controls (Ward et al. 2005). Adolescent male weightlifters have also been found to have significantly greater BMD or BMC than agematched controls (Conroy et al. 1993; Virvidakis et al. 1990). Conroy et al. (1993) have shown a significant relationship between BMD and muscle strength in this group of junior weightlifters, with strength accounting for $30-65 \%$ of variance, whereas in the Virvidakis et al. (1990) study, BMC was highly correlated with weight record. Furthermore, Nichols et al. (2001) compared a group of 13-17 years old females assigned to an RT intervention group three times a week for 15 months with a control group of age-matched females. They reported no significant changes in the lumbar BMD and bone mineral content in their RT group as compared to the control group. The only difference between the groups was an increased leg strength and femoral neck BMD in the RT group. Based on the skeletal benefits described (Table 1), RT beginning at a young age is also associated with a decreased risk of osteoporotic fractures later in life (Heinomen et 
al. 2000). Childhood through late adolescence is a crucial period in bone formation, with about $50 \%$ of the peak bone mass being acquired during this period (Bonjour et al. 1991; Matkovic et al. 1994). Peak bone mass is defined as the amount of bony tissue present at the end of skeletal maturation. Because a low peak bone mass is a significant risk factor for osteoporosis and associated fractures, the attainment of an ample peak bone mass during childhood and adolescence is an effective method to reduce the risk for the later development of osteoporosis (Hansen et al. 1991).

As the prevalence of childhood obesity continues to increase, the positive impact of RT on body composition in obese youths should be considered. A number of studies have been reported that regular participation in RT programs resulted in an improvement of body composition in obese children and adolescents (Sothern et al. 2000; Treuth et al. 1998; Watts et al. 2004). RT has also been used as a rehabilitation strategy in children with other chronic conditions. Selvandurai et al. (2002) studied three groups of children suffering from cystic fibrosis with pulmonary exacerbation: a group who participated in an aerobic training program, an RT group and a control group. They found that both the aerobic and RT groups had positive results as compared with the control group. More specifically, the RT group had improved lung function, leg muscle strength, and fat-free mass. Research studies also suggest that strength-training programs for children with cerebral palsy may help to increase muscle strength and improve daily activities and quality of life (Damiano et al. 1995, Dodd et al. 2002; McBurney et al. 2003; Morton et al. 2005). Further, Suman et al. (2001) conducted an intervention study in a group of children who had a total of greater than $40 \%$ of their body surface area burned. Patients were required to complete a 12-week exercise program at home or in the hospital's 
rehabilitation center. They were divided into two groups: the RT group, which participated in an individualized training program supervised by personal trainers, and a control group who were asked to complete a home-based rehabilitation program without exercise. The results of this study showed significant increases in muscle strength, total work resistance and lean body mass in the RT group as compared with the control home group.

Based on anecdotal evidence, it was believed that RT leads to injury of epiphyseal plates, cartilage, ligaments or muscles. However, prospective studies in children do not support this belief. Faigenbaum et al. (2003) examined the safety and efficacy of maximal strength testing in healthy children between the ages of 6 and 12 years in a controlled environment. During the intervention, the researchers asked the children about muscle pain, soreness and difficulty of movements at the end of each testing session and over a period of time. The study concluded that during supervised strength testing no injuries had occurred and no complaints were reported in both the boys and girls. In a previous study, Weltman et al. (1986) examined the effectiveness and safety of a 14-wk hydraulic resistance training program in 26 pre-pubertal males by using musculoskeletal scintigraphy to assess tissue damage. They found no evidence of damage to epiphyses, bone, or muscle as a result of strength training and concluded that in the short term, supervised concentric strength training using hydraulic resistance equipment is safe and effective in pre-pubertal boys (Weltman et al. 1986). The safety of a resistance training program in pre-pubescent to early post-pubescent males and females was also examined by Lillegard et al. (1997). Only one injury had been recorded during the 12-week training session. The injury, a minor strain of the shoulder muscle, was considered incidental due 
to the low exercise to injury ratio and the severity of this one injury (Lillegard et al. 1997). Injuries of the epiphyseal plates have been suggested to be less likely to occur during childhood than during adolescence, because the growth plates of children may actually be stronger and more resistant to various forces than those of adolescents (Micheli 1988). Further, although elite RT sports such as gymnastics have also been associated in the past with delayed growth and skeletal maturity recent research has shown that the shorter stature found in young gymnasts when compared with agematched controls is a result of selection rather than an effect of training on physical growth, because of an advantage of shorter athletes in the sport (Daly et al. 2000; Erlandson et al. 2008; Gurd and Klentrou 2003).

Recent studies appear to have come to a consensus regarding the beneficial effects of RT in young populations. Not only has it been found to be beneficial to healthy growing muscles and bones but it has also been found to help children suffering from various diseases or health conditions. On the other hand, there are many precautions that must be considered when practicing RT with children, the most important being proper technique and appropriate volume. As pointed out by Selvadurai et al. (2002), one must remember that even though RT aims at improving muscle strength, other forms of physical activity such as cardiorespiratory activities should be practiced on a regular basis in order to maintain a balanced and healthy lifestyle, optimize recovery time and improve cardiovascular growth and function.

Thus, there are numerous beneficial effects of RT in general, and in children in particular. Most notably these include an increase in muscle strength (Blimkie 1992; Blimkie 1993; Falk and Tenenbaum 1996; Payne et al. 1997; Sale 1989). Other beneficial 
effects include a potential increase in bone strength, a desirable change in body composition and an improvement in motor skills and sports performance. The next section focuses on the physiological mechanisms explaining the increase in muscle strength, highlighting the available evidence in children and the known differences between children and adults.

\section{Physiological Mechanisms}

There are two generally acceptable types of adaptations that may occur in response to RT and may explain the observed strength gains: morphological and neurological. The relative contribution of these adaptations may be different in children, adolescents and adults.

Morphological Adaptations

Morphological changes following RT include an increase in muscle size, primarily due to an increase in fibre size, potential hyperplasia, changes in fibre type composition and connective tissue, as well as structural changes in the muscle.

Commonly, morphological changes imply that muscle mass has increased or hypertrophy has occurred. This has been a common observation in adults, but not so much in children or adolescents. Although RT has been shown effective in increasing muscle strength in children and adolescents the reported increases in muscle size have been relatively small amongst studies. RT programs do not seem to influence growth in height and weights of pre- and early adolescent youth whereas changes in body composition, considering both fat and muscle mass, are minimal (Malina 2006, Falk and Eliakim 2003, Sadres et al. 2001). Studies examining whole muscle hypertrophy in children and adolescents have 
usually used anthropometric techniques and have provided very limited evidence of hypertrophy in adolescents (Lillegard et al. 1997), and no evidence of muscle hypertrophy in children (Blimkie 1989; Ozmun et al. 1994; Ramsay et al. 1990; Sailors and Berg 1987; McGovern 1984; Siegel et al. 1989), as a result of RT. However, two studies in which more sensitive methods of measurements were utilized (magnetic resonance imaging and ultrasound) have suggested that muscle hypertrophy may indeed occur among children following RT. Mersch and Stoboy (1989) used magnetic resonance imaging and were the first to demonstrate an increase in quadriceps crosssectional area, together with increases in knee extension isometric strength, in preadolescent boys. However, only two sets of twins participated in this study. Later, Fukunaga et al. (1992) used ultrasound to demonstrate increases in lean (muscle and bone) cross-sectional area among $1^{\text {st }}-3^{\text {rd }}$ grade Japanese boys and girls who engaged in RT (elbow flexion) over 12 weeks, whereas little change was observed in those children who did not train. Elbow flexors' cross-sectional area significantly increased but interestingly, the extensor's cross-sectional area increased to a similar extent. Given the small sample size in the study by Mersch and Stoboy (1989) and the somewhat inconsistent results of the study by Fukunaga et al. (1992), it may be premature to conclude that whole muscle hypertrophy does indeed occur in children as a response to RT. However, these two studies do present the prospect that muscle hypertrophy is possible among children, although these small potential changes may be difficult to measure.

In the above studies, the anatomical cross sectional area was measured. In both of the studies which did suggest hypertrophy in children (Mersch and Stoboy 1989; 
Fukunaga et al. 1992), as is the case in most studies examining hypertrophy in adults, the increases in muscle cross sectional area were much smaller than the increases in muscle strength. In other words, there was an increase in strength per whole muscle area, sometimes referred to as muscle specific tension. Theoretically, cross sectional area should be measured perpendicular to the line of pull of the fibres, called the physiological cross sectional area. However, this measurement is problematic and has not been attempted in children or adolescents following RT.

The increase in the cross sectional area of muscle as a result of RT in adults is primarily due to the hypertrophy of individual muscle fibres (McDonagh and Davies 1984; Jones et al. 1989). Changes in fibre cross sectional area in humans can only be examined using muscle biopsies. Given ethical considerations, it is understandable why such training-induced data do not exist in healthy children and adolescents. Nevertheless, if muscle hypertrophy does occur in children, it is likely due primarily to fibre hypertrophy. The latter is a result of myofibrillar growth (an increase in contractile proteins) and proliferation (an increase in the number of myofibrils), as well as satellite cells activation in the early stages of RT (Folland and Williams 2007). These mechanisms have not been investigated in children or adolescents.

The occurrence of hyperplasia as a result of RT remains controversial, but it has been suggested to take place in adults following such training (Appell et al. 1988; Kadi and Thornell 2000). However, this potential hyperplasia is argued to occur at a very slow rate and its contribution to strength gains is argued to be minimal (Appell 1990). In view of the need for muscle biopsy samples in order to investigate this issue, hyperplasia has not been examined in children. 
Other potential morphological effects of RT, which may explain increases in muscle strength, include changes in myosin heavy-chain and fibre type composition, increased tendinous stiffness and an increase in the angle of muscle pennation. Several studies have reported an increase in the number of type IIa fibres and a concomitant decrease in type IIx fibres in adults (Campos et al. 2002; Hakkinen et al. 1998; Hather et al. 1991; Staron et al. 1990), suggesting subtle fibre type changes. These have not been examined in children or adolescents. Tendinous stiffness has been demonstrated to increase following RT in adults (Kubo et al. 2001; Kubo et al. 2002; Reeves et al. 2003), reducing the electromechanical delay in the muscle and increasing the rate of force development. Although musculo-tendinous stiffness has been reported to be lower in children compared with adults in some (Lambertz et al. 2003) but not all studies (Cornu \& Goubel 2001), the effect of RT on tendinous stiffness in children and adolescents has not been investigated. Finally, recent studies in adults have provided strong evidence for an increase in the angle of pennation following RT (Aagaard et al. 2001; Kanehisa et al. 2002; Kawakami et al. 1995; Reeves et al. 2004), allowing for more myofibrillar packing and effectively increasing the physiological cross sectional area. An increase in the angle of pennation by itself is not necessarily advantageous. However, with an increase in myofibrillar packing, it would, in effect, increase muscle strength since most muscles in humans have an angle of pennation substantially lower than the optimal $45^{\circ}$. Although tendinous stiffness and angle of pennation can be examined using non-invasive techniques, the effects of RT on these characteristics have not been examined in children. Regardless of their potential existence in children, adolescents or adults, the morphological adaptations described above explain only a small portion of the increases 
observed in muscle strength among children and adolescents. More studies using sensitive techniques are needed to clarify the contribution of the various morphological adaptations to the strength gains observed in children following RT.

\section{$\underline{\text { Neurological Adaptations }}$}

In view of the limited evidence of muscle hypertrophy and its small potential contribution, strength gains among children have been attributed mainly to neurological adaptations. These adaptations are difficult to define but can be viewed as modifications in coordination and learning that facilitate better recruitment and activation of muscles involved in specific strength tasks (Folland and Williams 2007; Sale et al. 1983). Measurement of such adaptation is elusive, and therefore neurological adaptations are mainly based on indirect evidence.

In adults, indirect evidence of neural adaptations includes the disproportionately greater increase in muscle strength compared with the observed increases in muscle size. The case is similar in adolescents, where some hypertrophy has been demonstrated, but not sufficient to explain the increase in muscle strength. In children, since there is minimal evidence of an increase in muscle size, the neurological adaptations are inferred from strength gains that are not accompanied by muscle hypertrophy. In most cases, whether children, adolescents or adults, there is an increase in the specific tension (torque/size) of the muscle. However, as pointed out recently by Folland and Williams (2007), this increase in specific tension can be explained not only by neurological adaptations (see below), but also by some morphological adaptations, such as increases in tendinous stiffness or in the angle of pennation. 
No studies have specifically examined neurological adaptations in adolescents. There are only two studies that attempted to directly demonstrate neurological changes in children following RT. Using the interpolated twitch technique, Ramsay et al. (1990) demonstrated an increase of 9 and 12\% in motor unit activation of the elbow flexors and knee extensors, respectively, following 10 weeks of RT and an additional 3 and $2 \%$, respectively, following another 10 weeks of training. Nevertheless, the training-induced increases in strength were much greater than the concurrent increases in neuromotor activation. Likewise, Ozmun et al. (1994) used integrated electromyography amplitude (IEMG) to demonstrate an increase in neuromuscular activation in agonist muscles following eight weeks of RT in pre-pubertal boys and girls. As with the interpolated twitch technique, the increase in IEMG was smaller than the increases in strength (16.8\% vs. $27.8 \%$, respectively).

An increase in agonist's activation is likely to result in enhanced force production. However, the latter would also be a result of a decrease in antagonist activation, or improved inter-muscular coordination. Several studies have demonstrated lower antagonist co-activation in strength/power adult athletes compared with non-athletes (Baratta et al. 1988; Osternig et al. 1986). Similarly, some studies have indicated lower antagonist co-activation in adults compared with children (Frost 1997; Lambertz et al. 2003). Isometric training has been shown to decrease antagonistic co-activation during knee extension in adults (Carolan and Cafarelli 1992), but there are no comparative studies in children or adolescents. This type of adaptation likely has a greater influence on strength improvements in complex multi-joint movements, rather than in simple single-joint tasks. 
Neurological adaptations are believed to occur predominantly in the early phases of training (Moritani 1992; Sale 1989). This is supported by Ramsay et al.'s (1990) findings of greater increase in motor unit activation in children in the first 10 weeks, compared with the second 10 weeks of training, as cited above. In fact, the earliest phase of training likely involves the learning or optimization of inter-muscular coordination (agonists, synergists, stabilizers). Folland and Williams (2007) propose that the magnitude of this learning depends on prior physical activity level and experience in the specific task. This would suggest that children, being younger and generally less experienced or skillful in most tasks than adults, would exhibit greater neurological adaptations in response to RT. Indeed, based on the lack of observed morphological changes in children, this notion has been indicated in the past (Blimkie 1989; Sale 1996). The specificity of training has not been investigated in children. In adults, a lowrepetition-high load RT program is recommended to increase maximal strength. However, in 5-12 year-old children, Faigenbaum et al. (1999) demonstrated that highrepetition-low-load and low-repetition-high-load RT programs resulted in a similar enhancement of maximal strength. Thus, it is unclear whether the neurological adaptations to $\mathrm{RT}$ in children are specific to the training parameters, as would be expected in adults.

Thus, training-induced strength gains in children and adolescents may possibly be explained in part by muscle hypertrophy, but especially in children, are largely explained by neurological adaptations such as increased motor unit activation or other changes such as improved inter-muscle coordination or neuromuscular learning (Kraemer et al. 1989; Ozmun et al. 2994; Ramsay et al. 1990). The latter probably has a higher relative 
contribution in more complex, multi-joint actions (e.g., squat) than in single isometric contractions (e.g., of the knee extensors). The muscle learns to be more efficient due to this stimulus and it is not until puberty that the learned adaptation becomes permanent in the hypertrophic muscle (Malina 2006).

In view of the scarcity of findings, more research is required to elucidate the effect of different modes of training, as well as different training parameters (volume, intensity, frequency, duration), as well as the status of maturity, on the neurological adaptations to RT in children and adolescents, along with the morphological changes that possibly accompany these adaptations.

\section{Training Guidelines and Considerations}

Youth RT programs need to be carefully prescribed and progressed due to interindividual differences in physical maturation, training experience and stress tolerance. While there is no minimal age requirement for participation in a youth RT program, all participants should have a desire to resistance train and should be able to follow coaching instructions and comply with safety rules. In general, if a child is ready for sports participation (generally age seven or eight years), then he or she may be ready for some type of RT. A pre-participation medical exam is not required for apparently healthy children, but is recommended for youth with known or suspected health problems (e.g., diabetes, obesity, orthopedic ailments).

With age-appropriate instruction and competent supervision, regular participation in a youth RT program can offer observable health and fitness value to boys and girls and may foster favorable attitudes towards lifelong physical activity. However, over- 
prescription of RT and excessive pressure from coaches and parents to perform at a level beyond one's capabilities may result in overtraining, injury or burnout (American Academy of Pediatrics 2000; International Federation of Sports Medicine 1998). The prescription of RT programs should take into consideration the maturational status of the youth, training mode and extent and intensity of other activities. It is not uncommon for some youth to be involved in a number of sports/activities, which may limit the possible positive training adaptations that could be accrued from additional RT. The training and participation in multiple sports and activities highlight the need for periodized youth resistance training programs, which vary in volume and intensity throughout the season/year.

For that reason, adult exercise guidelines and training philosophies should not be imposed on youth since they are physically and psychologically less mature than adults.

Participation in a youth RT program should provide all participants with an opportunity to learn about their bodies, experience the benefits of resistance exercise, embrace self-improvement, and feel good about their performances. In addition, youth RT programs can include basic education on proper nutrition, adequate sleep, fitness conditioning, and, if age-appropriate, performance enhancing drug abuse. As such, the cognitive and physical maturity of each participant along with individual needs, goals and abilities need to be carefully considered. Since enjoyment has been shown to mediate the effects of youth physical activity programs (Dishman et al. 2005), the importance of creating an enjoyable exercise experience for all participants should not be overlooked.

A key factor in the design of any youth RT program is appropriate program design, which includes instruction on proper lifting techniques, correct prescription of the 
program variables and the inclusion of specific methods of progression. Since the act of RT itself does not ensure that optimal gains in health and fitness will be realized, youth RT programs need to be individually prescribed and sensibly progressed over time. Several specific areas of concern are important to consider when designing youth RT programs; the quality of instruction, type of warm-up, choice of exercise, training intensity and volume, and method of testing. Table 2 summarizes RT guidelines for children and adolescents.

\section{INSERT TABLE 2 HERE}

Quality of Instruction. Health and fitness professionals who have a thorough understanding of youth RT guidelines and safety procedures should provide instruction

and supervision for all participants. In addition, professionals should genuinely appreciate the developmental uniqueness of youth and should be able to present information to children and adolescents in a way that is appropriate for their level of understanding. Qualified instruction not only enhances participant safety, but direct supervision of youth RT programs can result in greater program adherence and increased strength gains as compared with unsupervised training (Coutts et al. 2004). While adults with less experience may assist professionals in the organization and administration of youth RT programs, it is unlikely they will be able to provide the level of instruction and supervision that is needed for safe and effective training. Professional certification in the area of strength and conditioning (e.g., Certified Exercise Physiologists or Certified Strength and Conditioning Specialists) is highly desirable.

Professionals need to be aware of the inherent risks associated with RT and should attempt to decrease this risk by matching the RT program to the needs and 
abilities of each participant. This is particularly important for untrained children who often overestimate their physical abilities (Plumert and Schwebel 1997). An advanced RT program for an adolescent athlete would be inappropriate for an untrained child who should be provided with an opportunity to learn basic training procedures and experience the mere enjoyment of resistance exercise. It is always better to underestimate the physical abilities of a child rather than overestimate them and risk negative consequences such as an injury.

Type of Warm-up. All participants should warm-up prior to RT. While a general warm-up of low intensity aerobic exercise and static stretching is a common practice prior to participation in recreational activities and athletic events (Martens 2004; Shehab et al. 2006; Virgilio 1997), long-held beliefs regarding the routine practice of pre-event static stretching have been questioned (Rubini et al. 2007; Shrier 2004; Thacker et al. 2004:). Recently, the effects of warm-up procedures that involve the performance of dynamic movements (e.g., lunges, skips, twists and throws) designed to elevate core body temperature, enhance motor unit excitability, improve kinesthetic awareness and maximize active ranges of motion have received increased attention (Faigenbaum and McFarland 2007; Verstegen and Williams 2004). Of note, a dynamic warm-up does not involve bouncing-type ballistic movements, but rather a controlled elongation of specific muscle groups.

Dynamic warm-up protocols that require balance, coordination, power and speed have been shown to enhance performance in children and adolescents (Faigenbaum et al. 2005a; 2006a; 2006b; Siatras et al. 2003) whereas pre-event static stretching has been shown to reduce lower extremity power and isokinetic peak torque in youth (McNeal and 
Sands 2003; Zakas et al. 2006). Furthermore, dynamic warm-up procedures require participants to become immediately engaged in class activities and ready to listen to instruction (Graham 2001). Since chronic static stretching is still recognized as a healthrelated component of physical fitness in physical education programs (National Association of Sport and Physical Education, 2005), a reasonable recommendation is to perform dynamic activities during the warm-up period and static stretching exercises which are relaxing and less intense during the cool-down session. These recommendations are consistent with others who suggest that static stretching should be performed after exercise (Fields, Burnworth, \& Delaney, 2007; Shrier, 2004).

Choice of Exercise. A limitless number of exercises can be used to enhance muscular fitness provided that the exercises are appropriate for a child's body size, fitness level, and exercise technique experience. Weight machines (both child- and adult-sized), free weights (barbells and dumbbells), elastic bands, medicine balls and body weight exercises have been shown to be safe and effective for children and adolescents (Annesi et al. 2005; Faigenbaum and Mediate 2006c; Faigenbaum et al. 2005b; Falk and Mor 1996; Ramsay et al. 1990; Sadres et al. 2001; Siegel et al. 1989). When deciding on equipment, realize that adolescents may be able to use adult-size weight machines but small children will not be able to position themselves properly on these large machines. Since children's smaller body size usually precludes the use of adult-sized equipment, child-size machines or other modes of training (e.g., dumbbells or medicine balls) are most appropriate for small children. Single-joint exercises (e.g., biceps curl and leg extension), which target specific muscle groups, and multi-joint exercises (e.g. bench press and back squat), which involve the coordinated action of many muscle groups, can 
be incorporated into a youth RT program. Regardless of the choice of exercise, the concentric and eccentric phases of each lift should be performed in a controlled manner with proper exercise technique.

For youth beginning RT, it is important to choose exercises that match abilities. As such, it is reasonable to start RT with simple exercises and gradually progress to more complex exercises as competence and confidence improve. Advanced multi-joint exercises including Olympic-style lifts (e.g., snatch and clean and jerk) and modified cleans, pulls and presses may be incorporated into a youth RT program (Faigenbaum et al. 2007a; Sadres et al. 2001). With qualified coaching and safety measures in place (e.g., safe lifting environment, appropriate loads), data indicate that risk of injury during the performance of Olympic-style lifts during training and weightlifting competition is relatively low (Byrd et al. 2003; Hamill 1994; Pierce et al. 1999). Nevertheless, Olympicstyle lifts involve a more complex neural activation pattern and therefore participants need to learn how to perform these lifts early in the workout with a relatively light load (e.g., wooden dowel or unloaded barbell) in order to develop coordination and skill technique without undue fatigue. As neural or learning adaptations are generally accepted as the major contributor to strength gains during preadolescence, the progression to more complex coordinated movements including Olympic style lifts may be permitted during this developmental period to potentially enhance neuromuscular organization.

Plyometric training or stretch-shortening cycle exercise can be safe and effective for enhancing muscle power in children and adolescents provided that appropriate training and guidelines are followed (Brown et al. 1986; Kotzamanidis 2006; Lephart et al. 2005; Marginson et al. 2005; Matavulj et al. 2001; Diallo et al. 2001). Past 
recommendations for adult plyometric training (i.e. the athlete should be able to squat at least 1.5 times his or her body weight before performing lower body plyometrics (Potach and Chu 2000) may have inhibited the implementation of plyometric training for youth. While these adult recommendations may be appropriate for high intensity or high amplitude plyometrics, children and adolescents regularly perform plyometrics when they skip, hop, run, bound and jump.

Typically, plyometric training involves body weight jumping exercises and medicine ball throws that are performed quickly and explosively. With plyometric training, the neuromuscular system is conditioned to react more quickly to the stretchshortening cycle. Thus, this type of training may enhance a young athlete's ability to increase speed of movement and improve power production (Chu et al.2006).

Youth should begin plyometric training with less intense drills (e.g., double-leg jumps) and gradually progress to more advanced drills (e.g., single leg hops) as competence and confidence to perform this type of training improve. Studies indicate that relatively few repetitions (i.e., $\leq 10$ ) of each plyometric drill are needed to bring about significant training-induced gains in performance (Lephart et al. 2005; Myer et al. 2005; Matavulj et al. 2001). Plyometric training should take place on yielding surfaces (e.g., gymnasium floor or playing field) and the focus of early training should be on proper athletic positioning and landing. Since plyometric training is not intended to be a standalone exercise program, the best approach is to incorporate this type of training into a well-rounded program which also includes other types of strength and conditioning (Faigenbaum et al. 2007b; Ingle et al. 2006; Myer et al. 2005). 
Exercises that require balance should also be incorporated into youth RT programs since balance is essential for optimal performance and the prevention of athletic injuries (Verhagen et al. 2005). In adults, balance is related to the ability to exert force and power and therefore the ability to maintain and/or control a body position can enhance the neuromuscular adaptations to RT (Anderson and Behm 2004). Typically, a stiffening strategy that decreases the magnitude and rate of voluntary movements is adopted when adult participants are presented with a threat of instability (Adkin et al. 2002; Carpenter et al. 2001). Thus, a RT program that includes exercises, which could improve stability or balance, could subsequently enhance force output, power and coordination. In support of these observations, significant correlations between skating performance and the static wobble board balance test have been reported in youth under 19 years of age (Behm et al. 2005b).

Given that balance and coordination are not fully developed in children (Payne and Isaacs 2005), balance training may be particularly beneficial for reducing the risk of injury while performing RT, particularly to the lower back. A number of studies in adults have demonstrated increased muscle activation of trunk muscles when performing activities on an unstable versus a stable surface (Anderson and Behm 2005; Behm et al. 2005a). The advantage of training on an unstable surface is that high activation can be achieved without the imposition of high resistive loads (Anderson and Behm 2004; Behm et al. 2005a). When incorporating balance training into a child's or adolescent's RT program, exercises should progress from simple static balance activities on stable surfaces to more complex static instability training using devices such as wobble boards, BOSU (both sides up) balls and stability balls (Behm and Anderson 2006). Over time, the 
program can be made more challenging by changing the base of support, the moment or lever arm of the body segment, the movement pattern, or the speed of motion.

Training Intensity and Volume. RT intensity refers to the amount of weight lifted during the performance of an exercise whereas training volume is typically estimated from the number of exercises performed per session, the repetitions performed per set and the number of sets performed per exercise. Training intensity and training volume have a direct impact on training adaptations and are dependent upon other factors including exercise order, repetition speed and rest interval length (Kraemer and Ratamess 2004).

Different combinations of sets and repetitions from single set protocols with a moderate load (Westcott 1992) to progressive training regimens consisting of three to five sets with loads ranging from $70 \%$ to $85 \% 1$ repetition maximum (RM) have proven to be safe and effective for youth (Ramsay et al. 1990). While there is not one combination of sets and repetitions that will be optimal for all participants, a reasonable approach is to begin RT with one or two sets of 8 to 15 repetitions with a light to moderate load (30-60\% $1 \mathrm{RM})$ on eight to twelve exercises. A training frequency of at least two nonconsecutive days per week is recommended, as RT only once per week may result in suboptimal adaptations (Faigenbaum et al. 2002). This type of program will provide an opportunity for beginners to learn proper lifting techniques while maximizing gains in muscular strength (Faigenbaum 2000; Kraemer and Fleck, 2005).

Youth with RT experience can gradually progress to more intense or voluminous workouts in order to target specific training objectives (i.e., strength, power, hypertrophy and/or muscular endurance). For example, the performance of three sets with heavier loads (e.g., 6 to $10 \mathrm{RM}$ ) performed to volitional fatigue can be used to increase maximal 
strength on large muscle group exercises (e.g., leg press or bench press). Depending on program goals and individual abilities, progression can also be achieved by enhancing movement speed during the performance of selected exercises (i.e., plyometric drills and Olympic-style lifts). It is important to note that not all exercises need to be performed for the same number of sets and repetitions and that in some cases less intense training can provide needed variation during long-term athletic training programs.

Although additional long-term training studies are needed to explore the effects of different RT programs on youth, the best approach is to vary the RT program over time in order to keep the training stimulus challenging and effective. This does not mean that every training session needs to be more intense or voluminous than the previous session, but over time the RT program need to be systematically varied in order to stimulate further adaptations and maximize gains (Kraemer et al. 2002). In the long term, program variation with adequate recovery between training sessions will allow children and adolescents to make even greater gains because their body will be able to adapt to even greater demands (Bompa 2000; Kraemer and Fleck 2005).

Method of Testing. Strength testing provides an opportunity for professionals to assess initial strength levels, identify muscle imbalances, develop individualized programs, and monitor progress. In addition, if presented and administered properly, strength testing can provide an incentive for young participants to resistance train regularly in order to improve their strength performance. While there are a variety of methods for evaluating muscular strength in children and adolescents (Gaul 1996), researchers typically used maximal load lifting (e.g., 1 RM), relatively high RM lifting (e.g., $10 \mathrm{RM}$ ), and maximal isokinetic tests to assess muscle strength in youth (Benson et 
al, 2007; Faigenbaum et al. 2003; Lillegard et al. 1997; Pfeiffer and Francis 1986;

Ramsay et al. 1990). No injuries have been reported in any prospective youth RT study that involved strength testing procedures. It should be underscored that strength testing in the aforementioned reports involved adequate warm-up, gradual progression of testing loads and close and competent supervision and instruction.

Although strength testing is not a prerequisite for participation in a youth RT program, professionals who have experience testing youth can administer strength tests to evaluate training-induced gains in muscular strength and muscular endurance. While field-based measures (e.g., push-up or modified pull-up) are appropriate for testing a large group of children (e.g., physical education class), the use of RM strength testing procedures may provide more useful information for professionals who need to assess strength performance in trained youth (e.g., youth sports program). Of note, RM testing procedures are labor intensive, time consuming and require close, qualified supervision. Unsupervised and poorly performed strength tests should not be carried out under any circumstances because of the potential for injury.

\section{$\underline{\text { Risks and Concerns }}$}

A traditional concern associated with youth RT involves the potential for injury to the epiphyseal plate or growth cartilage. While this type of injury is possible if proper training guidelines are not followed (Gumbs et al. 1982; Jenkins and Mintowt-Czyz 1986), an epiphyseal plate fracture has not been reported in any prospective youth RT study that was competently supervised and appropriately progressed. If children and adolescents are taught how to resistance train properly, it seems that the risk of injury to the growth cartilage is minimal. Moreover, data suggest that regular participation in a 
well-designed RT program does not negatively impact growth or maturation of youth (Falk and Eliakim 2003; Malina 2006). Traditional fears associated with youth RT have been replaced with more recent findings which indicate that regular participation in weight-bearing physical activities is essential for normal bone growth and development (Bass 2000; Vicente-Rodriguez 2006).

It seems the greatest concern for children and adolescents who resistance train is the risk of an overuse soft tissue injury, particularly to the lower back (Brady et al. 1982; Brown and Kimball 1983, Risser et al. 1990). These observations are consistent with other data, which suggest lower back pain is the number one musculoskeletal problem in North America in adults (Coyte and Ashe 1998). Since weak musculature, improper lifting techniques or improperly designed RT programs may explain, at least in part, these observations, professionals need to be aware of the inherent risks associated with RT and should attempt to decrease this risk with proper instruction and program design. As such, professionals should include progressive strengthening exercises for the hips, abdomen and lower back in youth RT programs as part of a preventative health measure.

While all types of physical activity carry some degree of risk of musculoskeletal injury, the risk of injury of RT can be minimized with appropriate overload, gradual progression, careful selection of exercises and adequate recovery between training sessions. Of note, youth should not resistance train on their own without guidance from qualified professionals and, when appropriate, a spotter should be nearby in case of a failed repetition. Each participant must be treated as an individual due to the variability in children and adolescents of the same age to tolerate stress. Prescribing a RT program that exceeds a child's ability may undermine enjoyment of the training experience and may 
increase the risk of an acute or overuse injury. Qualified supervision, age-appropriate program design, safe exercise equipment and a clean training environment are paramount.

\section{Conclusions}

In summary, a properly supervised and instructed RT program using appropriately sized equipment, exercises within the child's or adolescent's capability and employing gradual progression can be implemented for youth. It has been well documented that optimal growth and development of the musculoskeletal system is achieved when progressive overload stresses are placed on the system. RT is one activity that can provide these results whereas other sport and play activities that involve dynamic movement of body mass over extended periods can also provide positive adaptations. RT exercises can range in complexity from simple body weight, dumbbell or machine type resistance exercises to more advanced techniques such as plyometrics, instability RT devices and Olympic style lifting. Training-related physiological adaptations include neurological adaptations with an emphasis on learning and co-ordination, with limited evidence of muscle hypertrophy. However, more research is necessary regarding the physiological mechanisms of strength gains in children and adolescents as a result of RT. These mechanisms include muscle hypertrophy, hyperplasia, fibre type transformation, changes in tendinous stiffness, angle of pennation, motor unit recruitment, muscle activation and antagonist co-contractions to name a few. Implementing a RT program for children and adolescents may not only improve muscular strength, endurance, power and 
balance but there is evidence for improvements in body composition and motor skills as well as functional performance improvements for individuals coping with cystic fibrosis, cerebral palsy and burns. 


\section{References}

Aagaard, P., Andersen, J.L., Dyhre-Poulsen, P., Leffers, A.M., Wagner, A., Magnusson, S.P., Halkjaer-Kristensen J, Simonsen EB. 2001. A mechanism for increased contractile strength of human pennate muscle in response to strength training: changes in muscle architecture. J. Physiol. 534, 613-23.

Adkin, A. L., Frank, J. S., Carpenter, M. G., and Peysar, G. W. 2002. Fear of falling modifies anticipatory postural control. Exper. Brain Res. 143, 160-170.

American Academy of Pediatrics. 2000. Intensive training and specialization in young athletes, Pediatrics, 106: 154-157.

American Academy of Pediatrics 2001. Strength training by children and adolescents. 107: $1470-1472$

American College of Sports Medicine. 2006. ACSM's Guidelines for Exercise Testing and Prescription, $7^{\text {th }}$ ed. Philadelphia, PA: Lippincott, Williams \& Wilkins.

Anderson K., and Behm, D. G. 2004. Maintenance of EMG Activity and Loss of Force Output With Instability. J. Strength Condition. Res. 18: 637-640. 
Anderson, K., and Behm, D. G. 2005. Trunk Muscle Activity Increases with Unstable Squat Movements. Can. J. Appl. Physiol. 30: 33-45.

Annesi J, Westcott W, Faigenbaum A., and Unruh, J. 2005. Effects of a 12-week physical activity protocol delivered by YMCA after-school counselors (Youth Fit for Life) on fitness and self-efficacy changes in 5-12 year old boys and girls. Res. Quart. Exerc. Sport 76: 468-476.

Appell, H.J. 1990. Muscular atrophy following immobilisation. A review. Sports Med. 10: $42-58$.

Appell, H.J., Forsberg, S., and Hollmann, W. 1988. Satellite cell activation in human skeletal muscle after training: evidence for muscle fiber neoformation. Int. J. Sports Med. 9: 297-9.

Baratta, R., Solomonow, M., Zhou, B.H., Letson, D., Chuinard, R., and D'Ambrosia, R. 1988. Muscular coactivation. The role of the antagonist musculature in maintaining knee stability. Am. J. Sports Med. 16: 113-22.

Bass, S. 2000. The prepubertal years: a uniquely opportune stage of growth when the skeleton is most responsive to exercise? Sports Med. 39: 73-78. 
Bass, S., Pearce, G., Bradney, M., Hendrich, E., Delmas, P.D., Harding, A., and Seeman, E. 1998. Exercise before puberty may confer Residual benefits in bone density in adulthood: studies in active prepubertal and retired female gymnasts. J. Bone Mineral Res. 13: 500-507.

Behm, D. G., and Anderson, K., 2006. The Role of Instability with Resistance Training. J. Strength Condition. Res. 20: 716-722.

Behm, D. G., Leonard, A., Young, W., Bonsey, A., and MacKinnon, S. 2005a. Trunk muscle EMG activity with unstable and unilateral exercises. J. Strength Condition. Res. 19: 193-201.

Behm, D. G., Wahl, M. J., Button, D. C., Power, K. E., and Anderson, K. G. 2005 b. Relationship between hockey skating speed and selected performance measures. J. Strength Cond. Res. 19: 326-331.

Benson, A.C., Torade, M.E., and Fiataroe Singh, M.A. 2007. A rational and method for high-intensity progressive resistance training with children and adolescents. Contemp. Clin. Trials, 28: 442-250.

Blimkie, C.J. 1989 Age- and sex-associated variation in strength during childhood: Anthropometric, morphologic, neurologic, biomechanical, endocrinologic, genetic, and physical activity correlates. In Gisolfi, C.V. (ed.), Perspectives in Exercise Science and 
Sports Medicine: Youth, Exercise and Sports, Benchmark Press, Indianapolis, IN, Vol. 2, pp. 99-163.

Blimkie, C.J. 1992. Resistance training during pre- and early puberty: efficacy, trainability, mechanisms, and persistence. Can. J. Sport Sci., 17: 264-79.

Blimkie, C.J. 1993. Resistance training during preadolescence. Sports Med. 15: 389-407.

Blimkie, C.J.R., Martin, J., Ramsay, J., Sale, D., and MacDougall, D. 1989. The effects of detraining and maintenance weight training on strength development in prepubertal boys. Canadian J. Sports Sci. 14: 104P.

Bompa, T. 2000. Total Training for Young Champions. Champaign, IL: Human Kinetics.

Brady, T, Cahill B, and Bodnar, L. 1982. Weight training related injuries in the high school athlete. Am. J. Sports Med. 10:1-5.

British Association of Sport and Exercise Science. 2004. BASES position statement on guidelines for resistance exercise in young people. J. Sport Sci., 22: 383-390.

Brown, E., and Kimball R. 1983. Medical history associated with adolescent power lifting. Pediatrics, 72:636-644. 
Brown, M., Mayhew, J., and Boleach, L. 1986. Effect of plyometric training on vertical jump performance in high school basketball players. J. Sports Med. 26, 1-4.

Byrd, R., Pierce, K., Rielly, L., and Brady, J. 2003. Young weightlifters' performance across time. Sports Biomechanics, 2: 133-140.

Campos, G.E., Luecke, T.J., Wendeln, H.K., Toma, K., Hagerman, F.C., Murray, T.F. Ragg K.E., Ratamess N.A., Kraemer W.J., Staron R.S. 2002. Muscular adaptations in response to three different resistance-training regimens: specificity of repetition maximum training zones. Eur. J. Appl. Physiol. 88: 50-60.

Carolan, B. and Cafarelli, E. 1992. Adaptations in coactivation after isometric resistance training. J. Appl. Physiol. 73: 911-7.

Carpenter, M. G., Frank, J. G., Silcher, C. P., and Peysar, G. W., 2001. The influence of postural threat on the control of upright stance. Exp. Brain Res. 138: 210-218.

Chu D, Faigenbaum A, and Falkel J. 2006. Progressive Plyometrics for Kids. Monterey, CA: Healthy Learning.

Cornu C, Goubel F. 2001. Musculo-tendinous and joint elastic characteristics during elbow flexion in children. Clin. Biomech. 16(9):758-64. 
Coutts, A., Murphy, A., and Dascombe, B. 2004. Effect of direct supervision of a strength coach on measures of muscular strength and power in young rugby league players. J. Strength Condition. Res. 18: 316-323.

Coyte, P. C. and Ashe, C. V., 1998. The economic cost of musculoskeletal disorders in Canada. Arthritis Care Res. 11: 315-325.

Christou, M., Smilios, I., Sotiropoulos, K., Volaklis K., Pilianidis, T., and Tokmakidis, S. 2006. Effects of resistance training on the physical capacities of adolescent soccer players. J. Strength Cond. Res. 20: 783-791.

Daly, R.M., Rich, P.A., Klein R., and Bass. S.L. 2000. Short stature in competitive prepubertal and early pubertal male gymnasts: the result of selection bias or intense training? J. Pediatr. 137: 510-516.

Diallo, O., Dore, E., Duche, P., and Van Praagh, E. 2001. Effects of plyometric training followed by a reduced training programme on physical performance in prepubescent soccer players. J. Sports Med. Phys. Fitness 41: 342-348.

Dishman R, Motl, R, Saunders, R, Felton, G., Ward, D., Dowda, M., and Pate, R. 2005. Enjoyment mediates effects of a school-based physical-activity intervention. Med. Sci. Sports Exerc. 37: 478-87. 
Erlandson, M.C., Sherar, L.B., Mirwald, R.L., Maffulli, N., Baxter-Jones, A.D. 2008. Growth and maturation of adolescent female gymnasts, swimmers, and tennis players. Med. Sci. Sports Exerc. 40: 34-42.

Faigenbaum, A. 2000. Strength training for children and adolescents. Clinics Sports Med. 19: 593-619.

Faigenbaum, A. 2007. Resistance training for children and adolescents: Are there health outcomes? Am. J. Lifestyle Med. 1:190-200.

Faigenbaum, A., Bellucci, M, Bernieri, A. Bakker, B., and Hoorens, K. 2005a. Acute effects of different warm-up protocols on fitness performance in children. J. Strength Cond. Res. 19: 376-381.

Faigenbaum, A., Glover, S., O’Connell, J., LaRosa Loud, R and Westcott, W. 2001. Effects of different resistance training protocols on upper body strength and endurance development in children. J. Strength Cond. 15: 459-465.

Faigenbaum, A., Kang , J., McFarland, J., Bloom, J., Magnatta, J., Ratamess, N., and Hoffman, J. 2006a. Acute effects of different warm-up protocols on anaerobic performance in teenage athletes. Ped. Exerc. Sci. 17: 64-75. 
Faigenbaum, A. D., Kraemer, W. J., Cahill, B., Chandler, J., Dziados, J., Elfrink, L. D., Formann, E., Gaudiose, M., Micheli, L., Nitka, M., and Roberts, S. 1996b. Youth resistance training: Position statement paper and literature review. Strength \& Conditioning, December: 62-75.

Faigenbaum A., and McFarland J. 2007. Guidelines for implementing a dynamic warmup for physical education. J. Phys. Ed. Rec. Dance 78: 25-28.

Faigenbaum, A., McFarland, J., Johnson, L., Kang, J., Bloom, J., Ratamess, N., and Hoffman, J. 2007a. Preliminary evaluation of an after-school resistance training program for improving physical fitness in middle-school-aged boys. Percep. Motor Skills, 104: 407-415.

Faigenbaum, A, McFarland, J., Keiper F., Tevlin W., Kang J., Ratamess N., and Hoffman J. 2007b. Effects of a short term plyometric and resistance training program on fitness performance in children age 12 to 15 years. J. Sports Sci. Med., 6: 519-525.

Faigenbaum, A. J. McFarland, J. Schwerdtman, N. Ratamess, J. Kang, and Hoffman J. 2006b. Dynamic warm-up protocols, with and without a weighted vest, and fitness performance in high school female athletes. J, Athletic Training, 41: 357-363 
Faigenbaum, A., and Mediate, P. 2006. The effects of medicine ball training on fitness performance of high school physical education students. The Physical Educator, 63: 160167.

Faigenbaum, A., Milliken, L., Moulton, L., and Westcott, W. 2005b. Early muscular fitness adaptations in children in response to two different resistance training regimens. Ped. Exerc. Sci. 17: 237-248.

Faigenbaum, A. Milliken, L., LaRosa Loud, R., Burak, B., Doherty, C. and Westcott, W. Comparison of 1 and 2 days per week of strength training in children. 2002. Res. Q.

Exerc. Sport 73: 416-424.

Faigenbaum, A.D., Milliken, L.A., and Westcott, W.L. 2003. Maximal Strength Testing in Healthy Children. J. Strength Cond. Res. 17: 162-166.

Faigenbaum A, Westcott W, Loud R, and Long C. 1999. The effects of different resistance training protocols on muscular strength and endurance development in children. Pediatrics 104(1): e5.

Faigenbaum A.D., Wescott W.L., and Micheli L.J. 1996a. The effects of strength training and detraining on children. J. Strength Cond. 10: 109-114. 
Faigenbaum, A., Zaichkowsky, L., Westcott, W., Micheli, L., and Fehlandt, A. 1993. The effects of twice-per-week strength training program on children. Ped. Exerc. Sci. 5: 339346.

Falk, B, and Eliakim, A. 2003. Resistance training, skeletal muscle and growth. Pediatr. Endocrinol Rev. 1:120-127.

Falk, B., and Mor, G. 1996. The effects of resistance and martial arts training in 6- to 8year old boys. Pediatr. Exerc. Sci. 8: 48-56.

Falk, B., and Tenenbaum, G. 1996. The effectiveness of resistance training in children. A meta-analysis. Sports Med, 22: 176-186.

Fields, K., Burnworth, C., and Delaney, M. 2007. Should athletes stretch before exercise? Gatorade Sports Science Institute Sports Science Exhange. 20: 1-6.

Folland, J.P., and Williams, A.G. 2007. The adaptations to strength training: morphological and neurological contributions to increased strength. Sports Med. 37: 145168.

Frost, G., Dowling, J., Dyson, K., and Bar-Or, O. 1997. Cocontraction in three age groups of children during treadmill locomotion. J. Electromyogr. Kinesiol., 7: 179-186. 
Fukunaga, T., Funato, K. and Ikegawa, S. 1992. The effects of resistance training on muscle area and strength in prepubescent age. Ann. Physiol. Anthropol. 11: 357-364.

Garhammer, J. 1993. A review of power output studies of Olympic and powerlifting. Methodology, performance prediction and evaluation tests. J. Strength Cond. Res. 7: 76-89.

Gaul, C. 1996. Muscular strength and endurance. In: Measurement in Pediatric Exercise Science. D. Docherty, (ed). Champaign, IL: Human Kinetics. pp. 225-254

Golan, R., Falk, B., Hoffman, J., Hochberg, Z., Ben-Sira, D., and Barak, Y. 1998. Resistance training for children and adolescents. Position statement by the International Federation of Sports Medicine (FIMS). Position Statement for the International Federation of Sports Medicine 265-270.

Graham, G. 2001. Teaching Children Physical Education, $2^{\text {nd }}$ ed. Champaign, IL: Human Kinetics.

Gumbs, V., Segal D., Hallihan J, and Lower, G. 1982. Bilateral distal radius and ulnar fractures in adolescent weight lifters. Am. J. Sports Med. 10: 375-379.

Gurd, B., and Klentrou, P. 2003. Physical and pubertal development in young male gymnasts. J. Appl. Physiol. 95: 1011-1015. 
Hakkinen, K., Newton, R.U., Gordon, S.E., McCormick, M., Volek, J.S., Nindl, B.C., Gotshalk, L., Campbell, W.W., Evans, W.J., Hakkinen, A., Humphries, B.J., Kraemar, W.J. 1998. Changes in muscle morphology, electromyographic activity, and force production characteristics during progressive strength training in young and older men. J. Gerontol. A Biol. Sci. Med. Sci, 53: B415-423.

Hamill B. 1994. Relative safety of weight lifting and weight training. J. Strength Cond. Res. 8: 53-57.

Hansen, M.A., Overgaard, K., Riis, B.J., Christiansen, C. 1991. Role of peak bone mass and bone loss in postmenopausal osteoporosis: 12 year study. BMJ. 303: 961-964.

Hass, C.J., Feigenbaum, M.S., and Franklin, B.A. 2001. Prescription of resistance training for healthy populations. Sports Med. 31: 953-964.

Hather, B.M., Tesch, P.A., Buchanan, P. and Dudley, G.A. 1991. Influence of eccentric actions on skeletal muscle adaptations to resistance training. Acta Physiol. Scand., 143: 177-85.

Heinone, A., Sievan, H., Kannus, P., Oja, P., Pasanen, M., Vouri, I. 2000. High-impact exercise and bones of growing girls: a 9-month control trial. Osteoporosis Int. 11: 10101017. 
Hind, K., and Borrows, M. 2007. Weight-bearing exercise and bone mineral accrual in children and adolescents: a review of controlled trials. Bone 51: 81-101.

Ingle, L., Sleap, M., Tolfrey, K. 2006. The effect of a complex training and detraining programme on selected strength and power variables in early prepubertal boys. J. Sports Sci., 24: 987-997.

International Federation of Sports Medicine. 1998. Excessive physical training in children and adolescents. In: Sports and Children, K. Chan, and L. Micheli, editors, Hong Kong, Williams and Wilkins Asia-Pacific, Ltd, pp.271-275

Jenkins, N., and Mintowt-Czyz, W. 1986. Bilateral fracture separations of the distal radial epiphyses during weight lifting. Br. J. Sports Med. 20: 72-73.

Jones, D.A., Rutherford, O.M. and Parker, D.F. 1989. Physiological changes in skeletal muscle as a result of strength training. Q. J. Exp. Physiol., 74: 233-56.

Kadi, F., and Thornell, L.E. 2000. Concomitant increases in myonuclear and satellite cell content in female trapezius muscle following strength training. Histochem. Cell Biol. 113: $99-103$. 
Kanehisa, H., Nagareda, H., Kawakami, Y., Akima, H., Masani, K., Kouzaki, M.

Fukunaga,T. 2002. Effects of equivolume isometric training programs comprising medium or high resistance on muscle size and strength. Eur. J. Appl. Physiol., 87: 112-9.

Kawakami, Y., Abe, T., Kuno, S.Y. and Fukunaga, T. 1995. Training-induced changes in muscle architecture and specific tension. Eur. J. Appl. Physiol. Occup. Physiol., 72: 3743.

Kotzamanidis C. 2006. Effect of plyometric training on running performance and vertical jumping in prepubertal boys. J. Strength Cond. Res. 20: 441-445,

Kraemer, W., Adams, K., Cafarelli, E., Dudley, G., Dooly, C., Feigenbaum, A., Fleck, M., Franklin, B., Fry, A., Hoffman, J., Newton, R., Potteiger, J., Stone, M., Ratamess, N., and Tripplett-McBride, T. 2002. Progression models in resistance training for healthy adults. Med. Sci. Sports Exerc. 34: 364-380.

Kraemer W, and Fleck S. 2005. Strength training for Young Athletes, $2^{\text {nd }}$ ed. Champaign, IL: Human Kinetics.

Kraemer, W and Ratamess, N. 2004. Fundamentals of resistance training: Progression and exercise prescription. Med. Sci. Sports Exerc. 36: 674-688. 
Kraemer, W.J., Fry, A.C., Frykman, P.N., Conroy, B., and Hoffman, J. 1989. Resistance training and youth. Pediatr. Exerc. Sci. 1: 336-350.

Kubo, K., Kanehisa, H. and Fukunaga, T. 2001. Effects of different duration isometric contractions on tendon elasticity in human quadriceps muscles. J. Physiol., 536: 649-655.

Kubo, K., Kanehisa, H. and Fukunaga, T. 2002. Effects of resistance and stretching training programmes on the viscoelastic properties of human tendon structures in vivo. J. Physiol. 538: 219-226.

Lambertz, D., Mora, I., Grosset, J.F. and Perot, C. 2003. Evaluation of musculotendinous stiffness in prepubertal children and adults, taking into account muscle activity. J. Appl. Physiol., 95: 64-72.

Lephart, S., Abt, J., Ferris, C., Sell, T., Nagai, T., Myers, J., and Irrgang, J. 2005. Neuromuscular and biomechanical characteristic changes in high school athletes: a plyometric versus basic resistance program. Br. J. Sports Med. 39: 932-938.

Lillegard W, Brown E, Wilson D, Henderson, R., and Lewis, E. 1997. Efficacy of strength training in prepubescent to early postpubescent males and females: effects of gender and maturity. Pediatric Rehabil. 1: 147-157. 
Malina, RM. 2006. Weight training in youth - growth, maturation, and safety: An evidence-based review. Clin. J. Sports Med. 16: 478-487.

Marginson V, Rowlands A, Gleeson N, Eston R. 2005. Comparison of the symptoms of exercise-induced muscle damage after and initial and repeated bout of plyometric exercise in men and boys. J. Appl. Physiol. 99: 1174-1181

Martens, R. 2004. Successful Coaching, $3^{\text {rd }}$ ed. Champaign, IL: Human Kinetics.

Matavulj, D., Kukolj, M., Ugarkovic J., Tihanyi J., and Jaric, S. 2001. Effects of plyometric training on jumping performance in junior basketball players. J. Sports Med. Physical Fitness 41: 159-164.

McDonagh, M.J., and Davies, C.T. 1984. Adaptive response of mammalian skeletal muscle to exercise with high loads. Eur. J. Appl. Physiol. Occup. Physiol. 52: 139-155.

McGovern, M. 1984. Effects of circuit weight training on the physical fitness of prepubescent children. Dissertation Abstracts International, 45: 452A-453A.

McNeal, J., and Sands, W. 2003. Acute static stretching reduces lower extremity power in trained children. Ped. Exerc. Sci. 15: 139-145. 
McNeely, E., and Armstrong, L. 2002. Strength training for children: a review and recommendations. Physical Health Educ. J. 68: 1-6.

Mersch, F., and Stoboy, H. 1989. Strength training and muscle hypertrophy in children. In Oseeid, S. and Carlson, K.H. (eds.), International Series on Sports Sciences. Children and Exercise XIII., Human Kinetics, Champaign, IL, pp. 165-192.

Micheli, L. 1988. Strength training in the young athlete. In: Brown, E., Branta, C (eds): Competitive Sports for Children and Youth. Champaign, IL: Human Kinetics, pp. 99105.

Moritani, T. 1992. Time course of adaptations during strength and power training. In Komi, P.V. (ed.), Strength and Power in Sport, Blackwell Sientific Publications, Oxford, The Encyclopaedia of Sports Medicine Vol. III, pp. 266-278.

Myer G., Ford, K., Palumbo, J., and. Hewett, T. 2005. Neuromuscular training improves performance and lower extremity biomechanics in female athletes. J. Strength Cond. Res. 19: 51-60.

National Association of Sport and Physical Education. 2005. Physical Education for Lifelong Fitness, $2^{\text {nd }}$ ed. Champaign, IL: Human Kinetics. 
Nichols, D.L., Sanborn, C.F., and Love, A.M. 2001. Resistance training and bone mineral density in adolescent females. J. Pediatr. 139: 473-475.

Osternig, L.R., Hamill, J., Lander, J.E., and Robertson, R. 1986. Co-activation of sprinter and distance runner muscles in isokinetic exercise. Med. Sci. Sports Exerc. 18: 431-435.

Ozmun, J.C., Mikesky, A.E., and Surburg, P.R. 1994. Neuromuscular adaptations following prepubescent strength training. Med. Sci. Sports Exerc. 26: 510-514.

Payne, V.G., and Isaacs, L.D. 2005. Human Motor Development. A Lifespan Approach. McGraw-Hill, Whitby, Ontario. Sixth Edition: pp. 78-80.

Payne, V.G., Morrow, J.R., Jr., Johnson, L., and Dalton, S.N. 1997. Resistance training in children and youth: a meta-analysis. Res. Q. Exerc. Sport 68: 80-88.

Pfeiffer R, and Francis, R. 1986. Effects of strength training on muscle development in prepubescent, pubescent and postpubescent males. Phys. Sports Med. 14: 134-143.

Pierce, K., Byrd R., and Stone, M. 1999. Youth weightlifting - Is it safe? Weightlifting USA 17: 5 . 
Pikosky, M., Faigenbaum, A., Westcott, W., Rodriguez, N. 2002. Effects of resistance training on protein utilization in healthy children. Med. Sci. Sports Exerc. 34: 820-827.

Plumert, J., and Schwebel, D. 1997. Social and temperamental influences on children's overestimation of their physical abilities: links to accidental injuries. J. Exp. Child Psychol., 67: 317-337.

Potach, D., and Chu, D. 2000. Plyometric Training, In: Essentials of Strength Training and Conditioning, $2^{\text {nd }}$. Edition, T. Baechle, R. Earle (Eds). Champaign, IL: Human Kinetics, pp 427-470

Ramsay, J.A., Blimkie, C.J.R., Smith, K., Garner, S., MacDougall, J.D., Sale, D.G. 1990. Strength training effects in pre-pubescent boys. Med. Sci. Sports Exerc. 22: 605-614.

Reeves, N.D., Maganaris, C.N., and Narici, M.V. 2003. Effect of strength training on human patella tendon mechanical properties of older individuals. J. Physiol. 548: 971981.

Reeves, N.D., Narici, M.V., and Maganaris, C.N. 2004. Effect of resistance training on skeletal muscle-specific force in elderly humans. J. Appl. Physiol. 96: 885-892.

Rians, C.B., Weltman, A., Cahill, B.R., Janney, C.A., Tippett, S.R., and Katch, F.I. 1987. Strength training for prepubescent males: is it safe? Am. J. Sports Med. 15: 483-489. 
Risser, W., Risser, J., and Preston, D. 1990. Weight training injuries in adolescents. Am. J. Dis. Child. 144: 1015-1017.

Rubini, E., Costa, A., and Gomes, P. 2007. The effects of stretching on strength performance. Sports Med. 37: 213-224.

Sadres, E., Eliakim, A., Constantini, N. Lidor, R., and Falk, B. 2001. The effect of long-term resistance training on anthropometric measures, muscle strength, and selfconcept in pre-pubertal boys. Ped. Exerc. Sci. 13: 357-372.

Sailors, M., and Berg, K. 1987. Comparison of responses to weight training in pubescent boys and men. J. Sports Med. Phys. Fitness 27: 30-37.

Sale, D.G. 1989. Strength training in children. In Gisolfi, C.V., Lamb, D.R. (ed.), Youth, Exercise and Sports, Benchmark Press, Carmel, IN, Perspectives in Exercise Science and Sports Medicine Vol. 2, pp. 165-222.

Sale, D.G., MacDougall, J.D., Upton, A.R. and McComas, A.J. 1983. Effect of strength training upon motoneuron excitability in man. Med. Sci. Sports Exerc. 15: 57-62.

Sale, D.G, Spriet, L.L. 1996 Skeletal muscle function and energy metabolism. In O. BarOr, D.R.L., P.M. Clarkson (ed.), Exercise and the Female - A Life Span Approach, 
Cooper Publishing Group, Carmel, IN, Perspectives in Exercise Science and Sports Medicine Vol. 19, pp. 289-359.

Selvadurai, C., Blimkie, C., Meyers, N., Mellis, C., Cooper, J., and Asperen, V. 2002. Randomized controlled study of in-hospital exercise training programs in children with cystic fibrosis. Ped. Pulmonol. 33: 194-200.

Shehab, R., Mirabelli, M., Gorenflo, D., and Fetters, M. 2006. Pre-exercise stretching and sports-related injuries: Knowledge, attitudes and practices. Clin. J. Sports Med. 16: 228-231.

Shrier, I. 2004. Does stretching improve performance? A systematic and critical review of the literature. Clin. J. Sport Med. 14: 267-273.

Siatras T, Papadopoulos G, Mameletzi D, Gerodimos V, and Kellis S. 2003. Static and dynamic acute stretching effect on gymnasts' speed in vaulting. Pediatr. Exerc. Sci. 15: 383-391.

Siegal, J.A., Camaione, D.N., and Manfredi, T.G. 1989. The effects of upper body resistance training on prepubescent children. Pediatr. Exerc. Sci. 1: 145-154.

Smith, A. D., Andrish, J. T., and Micheli, L. J., 1993. The prevention of sport injuries of children and adolescents. Med. Sci. Sports Exerc. 25: 1-7. 
Staron, R.S., Malicky, E.S., Leonardi, M.J., Falkel, J.E., Hagerman, F.C. and Dudley, G.A. 1990. Muscle hypertrophy and fast fiber type conversions in heavy resistancetrained women. Eur. J. Appl. Physiol. Occup. Physiol. 60: 71-9.

Steinberger, J. 2003. Diagnosis of the metabolic syndrome in children. Lipponcott Williams \& Wilkins Inc., New York, NY. 14 (6): 555-559.

Suman, O., Ricarda, J., Celis, M., Mlcak, R., and Herndon, D. 2001. Effect of a 12-wk resistance exercise program on skeletal muscle strength in children with burn injuries. J. Appl. Physiol. 91: 1168-1175.

Thacker, S., Gilchrist, J., Stroup, D, and Kimsey, C. 2004. The impact of stretching on sports injury risk: A systematic review of the literature. Med. Sci. Sports Exerc. 36: $371-378$.

Tsolakis, C. Vagenas, G., and Dessypris, A. 2004. Strength adaptations and hormonal responses to resistance training and detraining in preadolescent males. J. Strength Cond. Res. 18: 625-629.

Verstegen, M., and Williams, P. 2004. Core Performance. Rodale. 
Verhagen, E. A., van, Tulder M., van der Beek, A. J., Bouter, L. M., and van, Mechelen W. 2005. An economic evaluation of a proprioceptive balance board training programme for the prevention of ankle sprains in volleyball. Br. J. Sports Med. 39: 111-115.

Vicente-Rodriguez, G. 2006. How does exercise affect bone development during growth? Sports Med. 36: 561-569.

Virgilio, S. 1997. Fitness Education for Children. Champaign, IL: Human Kinetics.

Vrijens, J. 1978. Muscle strength development in the pre- and post-pubescent age. In: Borms J., Hebbelinck M, eds. Pediatric Work Physiology. Basel: Karger, pp. 152-158.

Ward, K.A., Robets, S.A., Adams, J.E., and Mughal, M.Z. 2005. Bone geometry and density in the skeleton of prepubertal gymnasts and school children. Bone 26: 1012-1018.

Webb G.M., 1990. Strength training in children and adolescents. Pediatr. Clin. North Am. 37: 1187-1210.

Weltman, A., Janney, C., Rians, C.B., Strand, K., Berg, B., Tippitt, S., Wise, J., Cahill, B.R., and Katch, F.I. 1986. The effects of hydraulic resistance strength training in prepubertal males. Med. Sci. Sports Exerc. 18: 629-689.

Westcott, W. 1992. A look at youth fitness. Am. Fitness Quart. 11: 16-19. 
Zakas, A., Doganis, G., Galazoulas, C., and Vamvakoudis, E. 2006. Effect of static stretching duration on isokinetic peak torque in pubescent soccer players. Ped. Exerc.

Sci. 18: 252-261. 